\title{
Branding in the Online Space: The Emerging Frontier of New-Age Marketing
}

\author{
Sachin Sinha \\ Sharda University, Greater Noida-201310 (UP), India \\ Deepti Sinha \\ JIMS, Greater Noida-201303 (UP), India
}

\begin{abstract}
Technology is proving to be both an enabler and a disabler as far as meaningful and effective brand experience is concerned. As humankind continues to march towards an elusive and illusive utopia of technological advancement, the personal touch of the brand experience is fast becoming a thing of the past.

While it cannot be denied that the modern methods of marketing are leaving no stone unturned in 'connecting' with the customer, but, ironically enough, it is the 'customer connect' itself, which is getting lost in the process. Modern marketing, in general, and its digital avatar, in particular, are creating what can be called an 'imaginary intimacy' with the customer. The poor Alice-like customer is being led into a Wonderland of false promises. The clueless customer is being hoodwinked into believing that the gadget on his palm or his lap or his desk is the repository of remedies for all maladies.

The biggest demerit of the digital revolution in marketing is that it has reduced consumer behaviour to a set of split-second reflex actions. The 'thinking consumer' is an endangered species now. This is a casualty of phenomenal proportions, which the marketer will realize to his detriment in the long run.
\end{abstract}

Key Words: Digital marketing, Customer connect, Brand experience

\section{INTRODUCTION}

The digital revolution has taken the world in its stride. It has brought about a cataclysmic change across the globe, a metamorphosis of sorts, which has engulfed the globally wide cross-section of consumers as well as all kinds of marketers along all latitudes and longitudes of the globe. The business models of industries have undergone a sea change and so have the permutations and combinations of consumer choices.

The digital revolution has come as a bolt from the blue for brand-building. Integrated marketing communications in the virtual world is potentially a very strong tool in the hands of marketers to create brand awareness and nurture brand identity. Brand-building is elaborate and pervasive in nature. It requires not just time and patience but also prolonged effort on a sustained basis.

Journal of Technology Management for Growing Economies Vol. 10, No. 1 April, 2019 pp. $19-27$

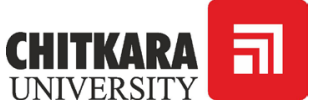

C2019 by Chitkara University. All Rights Reserved. 
Sinha, S.

Sinha, D.
Psychologically speaking, the long-drawn task of brand-building involves the construction of cognitive contours in the collective consciousness of consumers.

It involves creating concentric circles of favourable associations, happy memories and strong beliefs about the brand in the mind space of potential consumers, with the clear objective of making them preferentially pick up the promoted brand vis-a-vis the competing brands. This objective cannot be achieved overnight. It is an exercise that essentially stretches along a considerable length of time. The primary reason behind this task being too time-consuming is that it requires reinforcement. The brand marketer can provide this required reinforcement by iteratively exposing the potential consumer to brand stimuli. Ivan Pavlov's concept of classical conditioning comes into play here. Creation of customer conviction in favour of the particular brand has to happen before the buyer reaches the readiness stage to shell out money to buy the brand. Therefore, brand-building essentially requires the deployment of media vehicles that have a far-reaching audience. The underlying objective is to cover the entire prospective population and not just a specific sample. The objective is also not just to cover people who are engaged in the act of shopping at a given point of time but also to include those who are not. And the brand marketers cannot expect guaranteed attention as many members of the audience may not be at the market place at the time when they are exposed to the marketing-communications stimulus. Therefore, the tool that is pressed into service is emotional priming, which helps the marketer reach out to those people also who may not be interested in the product. Emotional priming also contributes to building long-term brand associations in the consumer's memory. The psychological logic used in this mechanism is that emotions usually have a greater impact on the mind than messages. Messages generally get filtered out from the cognition of the consumer. The marketing-communications campaigns that are centred around brand-building tend to produce the best possible results when consumers are induced to talk about the brand among themselves, when they are made to share notes about their vicariously formed perceptions about brands and also their real-life experiences with brands. Brands are basically social entities.

Digital marketing communications can also effectively contribute towards sales activation. As opposed to brand-building, the online communication campaigns that are targeted towards sales activation have a short-range time horizon. The people on the radar of the marketer are the ones who are intending to buy the brand in the immediate future. This actually implies that the brand marketer is trying to convert the accumulated and built-up brand equity into tangible and tactile sales. This time around there is no emotional build-up or no aura creation taking place. The central route to persuasion is resorted by the marketer, and the stress is on underscoring the utilitarian, rationally justified benefits of buying the brand. A 
very microscopically focused targeting of prospects is undertaken as part of this exercise. There are people out there who are waiting and willing to listen to what you have to say in terms of concrete points of advantage of buying the brand. The preferred media choices here are the ones that have the potential of conveying as much useful information as possible. If the dimension of interactivity can be included, nothing like it. This is a task that has to be executed in a short span of time, therefore, there is less scope for repetitively bombarding the brand stimuli onto the target market. In other words, it is important to ensure that the customers do not face any mental roadblocks in the this last leg of their journey leading to brand purchase.

Social media and instant messaging occupy a major fraction of our waking and working hours, and some form of online interaction or the other is usually on during most of the time we are awake. In the past one decade or so, social media and instant messaging have come to occupy $39 \%$ of the online time of consumers, and they have replaced electronic mail as the preferred mode of communication Binet, L. and Field, P. (2017). This is a big breakthrough for brand marketers, since social media and instant messaging represent more evolved forms of consumer communication, which can very customized for brand-building efforts. As compared to email, they are better equipped with more flexibility and more scope for innovativeness. Brand marketers always require the paid services of media advertising to cast their net of people connect. Their respective impact on the minds of the masses can be seen as a mathematical function of their respective share of voice. It all ultimately depends on who shouts the loudest. Brand research findings indicate that brands that have a relatively high share of voice end up having a market share growth rate and those with a low share of voice have a shrinking share of the market.

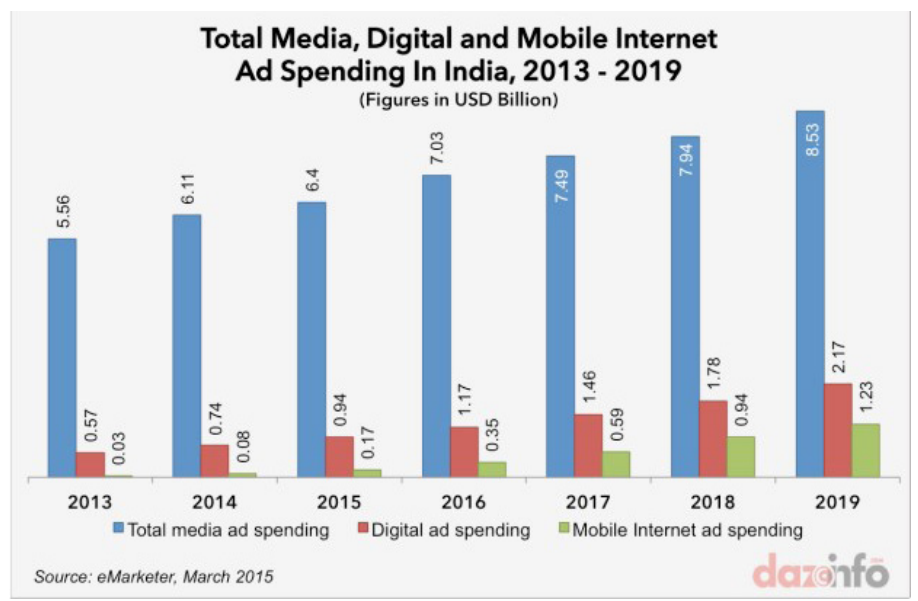

Figure 1: Ad spending in India
Branding in the Online Space 
Sinha, S.

Sinha, D.
Day by day people are getting more and more exposed to the digital media. This plays an important role in their purchasing decision and other aspects of consumer behaviour. They have started to look for product reviews and other relevant information prior to making a purchase. Marketers have started to observe this consumer tendency from close quarters and have started to spend a lot of money on different sources of digital media (Figure 1). It has been forcast that about more than one-third of global advertising spending will be through digital channels by 2020 eMarketer (2015). Thus, in future most of the branding and promotion will be carried out using online platforms, particularly social media and mobile (Figure 2).

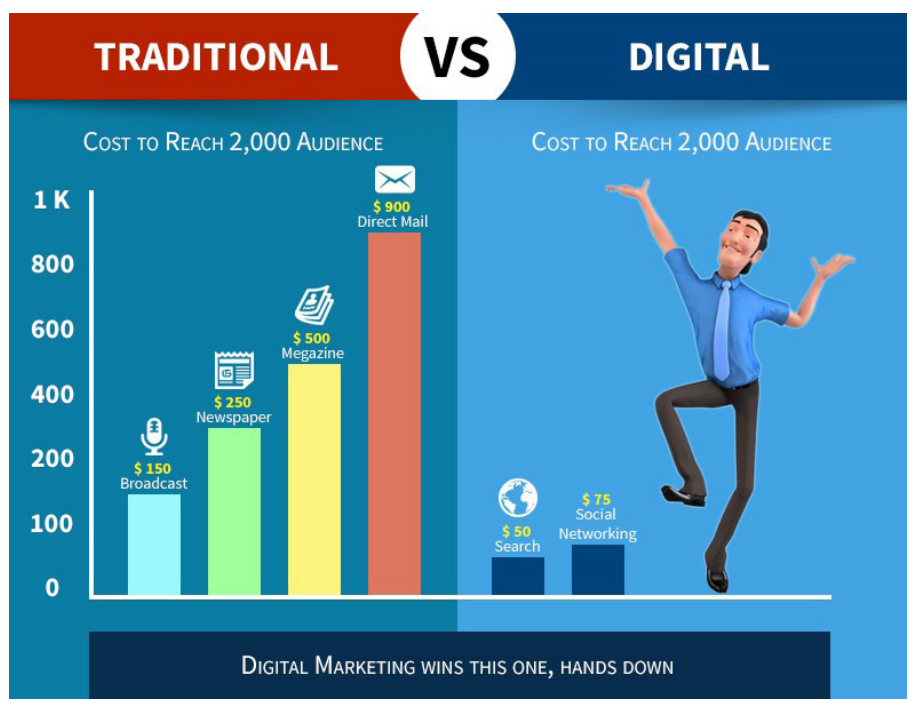

Figure 2: Cost to reach customers (Traditional Vs Digital approach)

Source:http://www.digitalvidya.com/blog/growth-of-digital-marketing-industry-in-india/ retrivedon 24.08 .19

\section{LITERATURE REVIEW}

Marketing is being driven by consumers due to the ever widening scope of the world wide web, Weber Shandwick (2012). In the process they are being enabled to strengthen as well as harm brand reputation. When they spread positive word of mouth on the online platform, they help in enhancing the brand reputation, on the other hand their bad reviews could cause great damage to the brands and marketers branding efforts. The sharing of positive product ratings might raise brand reputation while poor customer reviews are likely to portray brands in a negative light Karakaya and Barnese (2010). Individuals who are more active socially \& digitally are able to exercise their influence

Journal of Technology Management for Growing Economies, Volume 10, Number 1, April 2019 
on final purchase decisions of their friends and family. Not only this they can even influence the evaluation of brands and the fellow members purchase decisions Moran (2014). Dinner et al. (2014), brought to light the impact of digital display and search ads on online and offline purchasing for retailers and found that digital ads were more effective than offline ads in governing the online behavior. Lovett et al. (2013) found that online word of mouth (WOM) is driven by social and functional brand characteristics whereas offline WOM is driven by emotional brand characteristics. Study to identify differences in transmitting WOM in social media like Facebook, twitter, etc. and personally (offline mode), exhibited that consumers are cautious in transmitting WOM in social media because higher social risk is perceived online Eisingerich et al. (2015). At the same time, marketers invest in social media to create brand fans who tend to have positive effects on firm word of mouth and loyalty de Vries et al. (2012), Dholakia and Durham (2010).

Pearson in his research proposed the CARES (Contact, Affinity, Rewards, Extra value and Services) framework, as the steps for digital branding to achieve enhanced customer relationships in the internet environment, which may facilitate favourable customer buying behavior Pearson (1996). The significance of online brands may depend upon web experience, brand market share, and product category Danaher et al. (2003), Ward and Lee (2000). While analyzing the online branding it was found that although it starts with creating and registering logos, brand marks, brand strap lines, creating brand awareness and presence, but long-term success in online branding can only be achieved through the provision of a compelling and consistent offer, (the brand promise) backed by a positive customer experience (the brand experience) that ensures customer satisfaction and propels them to visit the site again and again, Rowley (2004). Fernandes, Rai \& Shetty have discussed a number of advantages and disadvantages of using online platforms for branding in their discussion paper, Fernandes et al. (2017) .

\section{CHALLENGES}

The digital space is gradually coming of age, and challenges are creeping into this arena also. Excessive and indiscriminate bombardment of stimuli onto the consumer population has created a conscious resistance from the receiving end. People are responding less to email communications as also to banner advertisements. There is also a greater tendency among netizens to block online advertisements. The metrics of online activity, like hits/clicks/likes/ shares, etc., are increasingly coming under the scanner. Some of the most commonly identified challenges for branding in digital world are Danaher et al. (2003):
Branding in the

Online Space 
Sinha, S.

Sinha, D.

1. According the status of 'assets' to brands: Brand marketers often feel compelled to produce commercial 'results' in the short run, which ultimately takes away their attention from the long-term task of building brand equity.

2. Breaking new ground in brand-building: Companies should strive hard to come up with path-breaking plans to create a lasting brand equity. Innovativeness of ideas and novelty of execution are the keys to sustainable brand-building. Creativity of ideas is more important than budgetary considerations. And it is not enough to be different. Also, it is also crucial to act fast. It is peremptory to convert one's creative ideas into marketplace reality, and that too with speed and alacrity.

3. Achieving the elusive goal of integrated marketing communications: Given the plethora of media choices that marketers have now, it is becoming increasingly difficult to achieve a near-perfect portfolio management of mass-media advertising. There is a sort of "cannibalization of communication as the different chosen media options tend to compete against each other, instead of creating a communication synergy. The possibility of collective reinforcement of ideas is less now because the different digital and non-digital marketing modes tend to operate in standalone silos instead of working in cooperative and collaborative sync with each other.

4. A brand needs a compulsive corporate vision: A brand should necessarily have a vision and that vision should be distinctive, should evoke an emotional resonance in the minds of consumers and should be a strong motivator for employees. The brand vision needs to be pragmatic and amenable to change. It should have the resilience to survive the turbulent dynamics of the marketplace. And should have the requisite horsepower to drive the engine of brand-building. It should have a multidimensional approach and the flexibility to be cast into different moulds.

5. Strategizing brand-building: The digital-marketing space needs to be approached with an entirely different perspective. The coordinates of this space are not easy to comprehend and are always in a state of flux. The controlling power lies in the hands of the recipients of the communication. A novel set of communication competencies, a refreshingly new look at things, breaking new grounds of creativity and compatibility of many modes of marketing, constitute the tool-kit for brand marketers in the digital space. The focus of attention of the digital marketer should essentially relocate from the product offering to the central life interest(s) of the consumer. Digital-marketing programmes should be designed around themes that are closest to the customer's head and heart.

Journal of Technology Management for Growing Economies, Volume 10, Number 1, April 2019 
6. Formation of new subdivisions of product categories: A wise way or warding off competition is to create new categories of products where competitors are yet to step in. The key is to outsmart the competitors by building invisible entry barriers fro them in these newly created sub-categories. This might demand a great deal of research and development and also a lot of perceptual re-engineering of the consumers.

\section{OVERCOMING CHALLENGES}

One crucial consideration in digital marketing communications is to avoid misdirected communication. The brand marketer should ensure that his words are not falling on deaf ears. The goal should be to reach out to the exact audience and not just hover around an approximate audience. The classical STP (segmentation, targeting, positioning) model should be pressed into service in digital brand marketing also. For the successful online branding a few important things which the marketers must take into consideration are Site Appearance, Location of the Brand, Navigation on page, Personal Support, Differential Reward, Personal Support, and Physical Delivery and Returns, and overall user interface. It would also be advisable to focus on building genuine relationships, enabling greater interactivity and developing customized offerings which are essential for creation of online brands. Having good networking with online communities is also good as they create more interactions amongst customers. Customers can interact through chatting, sharing a common message, commenting on post, and by recommending Fegade, A. (2013). Customers are constantly bombarded with a variety of options that are offered through innumerable sites. Marketers should do their best to gain a solid footing for their brand using strong and effective SEO (search engine optimization) techniques. Marketers should also keep track of the reviews posted by the customers,. Since it is something which is not in their control, they should be ready to rectify the false negative reviews, if any, and should not hesitate in appreciating and acknowledging those who have offered positive reviews. The digital marketer should engineer the online brand-search operations in such a manner that the brand is within easy reach of customers who are actively seeking a need satisfier. Further, efforts should also be made to target customers who have previously visited the site of the marketer, who have prior familiarity with the identity of the brand being promoted.

\section{CONCLUSIONS AND RECOMMENDATIONS}

Brand-building through the digital platform is an evolved form of mass marketing that needs to be executed with caution and care. The digital forum provides better-than-before opportunities for mass marketing, and companies

Journal of Technology Management for Growing Economies, Volume 10, Number 1, April 2019
Branding in the

Online Space 
Sinha, S. Sinha, D. are trying to cash in on this and make hay while the sun shines. But the outlook should be futuristic and forward-looking, rather than narrow and myopic. Brand-building through the digital mode requires ploughing in lots of money for long-range gains. The ideal ratio between brand-building and sales activation when it comes to investment of both efforts and funds should be 60:40.

Companies are unfortunately unable to harvest the optimum benefits out of the goldmine of opportunities that the digital revolution holds out for them. Marketers should strive to strike an optimum balance between long-term and short-term gains when it comes to leveraging the potential of the digital powerhouse. They should ensure that their brand campaigns do not diverge and digress from the core communication. The windfall gains of the immediate present as part of the digital drive for sales activation cannot be extrapolated to long-range results in terms of creation of sustainable brand equity.

Brand marketers in the digital space need to be be very wary and watchful of maintaining the requisite ratio of 60:40 between the brand-building and sales activation goals of their online branding programmes. The media planners need to monitor the progress of the digital campaigns to ensure that it does not go astray too much in either direction. The efforts of the marketers can bear fruit only if the twin objectives of brand image-building and generation of sales proceeds are achieved, without the two goals acting at cross-purposes with each other. Communication cannibalization could be the worst possible casualty.

\section{REFERENCES}

Aaker, D. (2014) "10 Most Common Branding Challenges", www.prophet.com. Available at: https://www.prophet.com/thinking/2014/09/the-10-most-common-branding-challenges/. (Accessed Jan. 24, 2019),

Binet, L. and Field, P. (2017) "Media in Focus: Marketing Effectiveness in the Digital Era", London:IPA.

Danaher P.J. Wilson I.W. and Davis R.A. (2003) "Comparison of Online and Offline Consumer Brand Loyalty", Marketing Science, 22(4), pp. 461-476. https://doi.org/10.1287/ mksc.22.4.461.24907

de Vries, L., Gensler, S., \& Leeflang, P. S. H. (2012) "Popularity of Brand Posts on Brand Fan Pages: An Investigation of the Effects of Social Media Marketing", Journal of Interactive Marketing, 26(2), pp. 83-91. https://doi.org/10.1016/j.intmar.2012.01.003

Dholakia, U. M., \& Durham, E. (2010) "One Café Chain's Facebook Experiment. Harvard Business Review, 88(3), pp. 26.

Dinner, Isaac M., Van Heerde, Harald J., and Neslin, Scott A. (2014), "Driving Online and Offline Sales: The Cross-Channel Effects of Traditional, Online Display, and Paid Search Advertising," Journal of Marketing Research, 51(5), pp. 527-545. https://doi.org/10.1509/jmr.11.0466

Eisingerich, Andreas B., Chun, HaeEun, Liu, Yeyi, Jia, He, and Bell, Simon J. (2015), "Why Recommend a Brand Face-to-face but not on Facebook? How word-of-mouth on online social sites differs from traditional word-of-mouth," Journal of Consumer Psychology, 25

Journal of Technology Management for Growing Economies, Volume 10, Number 1, April 2019 
(1), pp. 120-128. https://doi.org/10.1016/j.jcps.2014.05.004

eMarketer (2015) "Advertisers Will Spend Nearly \$600 Billion Worldwide in 2015, (Online) Available:http:/www.emarketer.com/Article/Advertisers-Will-Spend-Nearly-600-BillionWorldwide2015/1011691 (Accessed Jan. 24, 2019).

Fegade, A. (2013) "Online Branding: Building Powerful Brands through Online Social Media Networks", Chaitnya (Business Journal), pp. 1-9.

Fernandes, L., Rai, D. and Shetty, A. (2017) "Analysis of Insternet Branding Strategies", International Journal of Latest Trends in Engineering and Technology Special Issue SACAIM, 387-390.

Karakaya, F. \& Barnese, N.G. (2010) "Impact of Online Reviews of Customer Care Experience on Brand or Company Selection", Journal of Consumer Marketing, 27(5), pp. 447-457.

Kaur, J. (2017) "Digital Marketing Industry in India", Digital Vidya, 18th April 2017. Available at:http://www.digitalvidya.com/blog/growth-of-digital-marketing-industry-in-india/ (Accessed 24.08.19)

Lovett, Mitchell J., Peres, Renana, and Shachar, Ron (2013), "On brands and Word of Mouth," Journal of Marketing Research, 50(4), pp. 427-444. https://doi.org/10.1509/jmr.11.0458

Moran, G., Muzellec, L. \& Nolan, E. (2014) "Consumer Moments of Truth in the Digital Context: How 'Search' and 'E-Word of Mouth' can Fuel Consumer Decision Making”, Journal of Advertising Research, 54(2), pp. 200-204. https://doi.org/10.2501/JAR-54-2-200-204

Pearson S. (1996) "Building Brands Directly: Creating Business Value from Customer Relationships" New York University Press New York NY.

Rowley J. (2004) "Online Branding: The Case of McDonald's", British Food Journal. 106(3), pp. 228-237. https://doi.org/10.1108/00070700410528808

Ward M. and Lee M. (2000) "Internet Shopping, Consumer Search and Product Branding", Journal of Product and Brand Management. 9(1), pp. 6-20. https://doi.org/10.1108/10610420010316302

Weber Shandwick (2012) "The Company Behind the Brand: In Reputation We Trust " Available at: http://www.webershandwick.com/uploads/news/files/InRepWeTrust_ExecutiveSummary. pdf (Accessed Jan. 22, 2018)
Branding in the

Online Space 